\title{
ANALISIS PENGENDALIAN KOROSI PADA PERMUKAAN BASAH KAPAL- KAPAL BAJA DENGAN MENGGUNAKAN ZINK ANODA
}

\author{
Sonja T. A. Lekatompessy ${ }^{1, *}$ \\ ${ }^{1}$ Jurusan Teknik Perkapalan Fakultas Teknik Universitas Pattimura, Ambon 97233 \\ *Email: sonja.lekatompessy@gmail.com
}

\begin{abstract}
Abstrak. Zink anoda sangat penting untuk mereduksi laju korosi pada permukaan basah kapal. Zink anoda ditempelkan ke bagian-bagian kapal yang rawan terhadap korosi air laut. Penelitian ini memiliki tujuan untuk mengetahui seberapa besar pengaruh kuat arus terpasang terhadap laju korosi dengan cara melakaukan analisis terhadap data penggunaan zink anoda di lapangan dan data penggunaan zink anoda hasil perhitungan sehingga penggunaan kuat arus terpasang sesuai dengan kebutuhan akan mengurangi laju korosi. Untuk melihat pengaruh kuat arus terhadap laju korosi maka dibutuhkan data laju korosi 5 tahun terakhir dari 9 buah kapal dan juga jumlah zink anoda yang dipergunakan setiap tahunnya. Dari grafik hasil perhitungan kuat arus sesuai teori dan hasil pemakaian zink anoda pada sembilan kapal, hasil yang didapat terlihat jelas bahwa kuat arus terpasang harus mencukupi kebutuhan masing-masing kapal karena akan berpengaruh terhadap penurunan laju korosi.Pada Kapal No.3 ada kelebihan kuat arus 0,539Amp hingga 1,386 Amp terjadi penurunan laju korosi mencapai $0,0317 \mathrm{~mm} /$ tahun pada tahun ke-5. Pada kapal No. 4ada kelebihan kuat arus 0,444 Amp hingga 1,822 Amp terjadi penurunan laju korosi mencapai 0,0138 mm/tahun pada tahun ke-5.Pada kapal No. 9 ada kelebihan kuat arus 4,894 Amp hingga 5,793 Amp terjadi penurunan laju korosi mencapai $0,0371 \mathrm{~mm} /$ tahun pada tahun ke-5.
\end{abstract}

Kata kunci: Zink anoda, laju korosi

\begin{abstract}
Zink anodes are very importantfor reducing the corrosion rate on underwater surface area of hull plates. Zink anodes are affixed to parts of the vessel that are prone to seawater corrosion. This study aims to find out how much influence the installed current has on the corrosion rate by analyzing the data on the use of zink anodes in the field and the data on the use of zink anodes as a result of calculations so that the use of strong currents installed according to the need will reduce the rate of corrosion. To see the strong influence of current on the rate of corrosion, it takes data on the corrosion rate of the last 5 years from 9 vessels and also the number of zink anodes used each year. From the graph of the results of the calculation of strong current according to the theory and the results of the use of zinc anodes on nine vessels, the results obtained it is clear that the installed current strength must meet the needs of each vessel because it will affect the decrease in corrosion rate. On vessel No.3, an excess current strength of $0.539 \mathrm{Amp}$ to 1,386 Amp, a decrease in corrosion rate reaching $0.0317 \mathrm{~mm} / \mathrm{year}$ in the $5^{\text {th }}$ year. On vessel No. 4, an excess current strength of 0.444 Amp to 1.822 Amp there is a decrease in corrosion rate reaching $0.0138 \mathrm{~mm} /$ year in the $5^{\text {th }}$ year. On vessel No. 9 , an excess strong current of 4,894 Amp to 5,793 Amp there is a decrease in corrosion rate reaching $0.0371 \mathrm{~mm} /$ year in the $5^{\text {th }}$ year.
\end{abstract}

Keywords: Zink anode, corrosion rate

\section{PENDAHULUAN}

Kapal terbuat dari baja, komponen utamanya adalah besi. Besi adalah elemen positif elektrokimia yang memiliki kecenderungan untuk melepaskan elektron untuk menjadi ion bebas. Air laut terdiri dari oksigen dan hidrogen, dan 
menghasilkan ion hidroksil negatif elektrokimia yang dapat menerima elektron yang diberikan oleh Besi. Dengan cara ini ion Besi dikombinasikan dengan ion hidroksil air untuk membentuk Iron Hydroxide. Ini disebut oksidasi Zat Besi atau dikenal sebagai korosi [1].

Sistem anoda korban yang dirancang sesuai dengan kebutuhan akan mencegah korosi pada permukaan selama pelat baja tercelup dalam air [2].

Zink anoda digunakan untuk perlindungan cathodic, kemudian pengaruh waktu pencelupan $(10,20$, dan 30 hari) dan jarak anoda dari katoda $(1,2$, dan $3 \mathrm{~cm})$ diteliti. Perlindungan terbaik untuk korosi diperoleh pada waktu pencelupan 10 hari dan jarak elektroda $1 \mathrm{~cm}$, memungkinkan tingkat korosi 0,694 mpy dengan efisiensi $81,8 \%$ [3].

Proses reaksi perlindungan cathodic dievaluasi dengan metode penurunan berat, perhitungan tingkat korosi dan metode pengukuran potensial. Efektivitas zink anoda korban ditemukan secara cathodically protektif pada baja ringan dalam asam klorida pada suhu ruangan $\left(27^{\circ} \mathrm{C}\right)$ dan suhu tinggi $\left(60^{\circ} \mathrm{C}\right)$. Ada korelasi dekat dari hasil yang diperoleh untuk metode penurunan berat dan pengukuran potensial [4].

Pemasangan zink Anoda pada lambung kapal general kargo untuk mencegah korosi dikaitkan dengan jumlah dan umur zink anode adalah berlebihan sehingga perbandingan umur pakai dari hasil perhitungan dapat dijadikan sebagai pedoman [5].

Hasil pengujian memperlihatkan korosi dan laju korosi terjadi pada pelat tanpa perlindungan anoda baik pada sampel diam maupun pada sampel berputar. Perlindungan katode pada sampel diam menunjukkan laju korosi yang rendah pada pelat baja, sedangkan pada sampel berputar laju korosi terjadi pada pelat walaupun telah diberikan perlindungan. Pada sampel berputar, semakin tinggi laju korosi pada anode korban maka semakin rendah laju korosi pada pelat baja yang dilindunginya [6].

Berdasarkan hasil perhitungan kebutuhan anoda korban sesuai dasar pembahasan pada KMP. Citra Mandala Sakti, secara teknis dapat diketahui bahwa untuk memperlambat laju korosi plat lambung area bawah garis air kapal selama 3 tahun berlayar, dibutuhkan anoda korban paduan zink sebanyak $8 \mathrm{~kg} \times 21$ buah. Anodba korban paduan zink yang dipasang pada plat lambung kapal secara arus ternyata dapat memperlambat laju korosi rata-rata sebesar $0,308 \mathrm{~mm} /$ tahun [7].

Tes pengukuran korosi menggunakan metode penurunan berat dan polarisasi potentiodinamik.
Dari studi eksperimental, ditemukan bahwa tingkat korosi baja ringan berbanding terbalik dengan ketebalan lapisan zink.. Hasilnya menunjukkan bahwa tingkat korosi baja ringan dengan tes semprotan garam lebih tinggi daripada tes pencelupan [8].

Desain penelitian dilakukan dengan memvariasikan jenis anoda dalam bentuk $\mathrm{Al}$, anoda untuk jarak katoda $1 \mathrm{~cm}, 2 \mathrm{~cm}, 3 \mathrm{~cm}$. Data diproses dengan menggunakan metode penurunan berat badan dengan unit (mpy). Perlindungan terbaik terjadi pada perendaman 15 hari, dengan menggunakan $\mathrm{Al}$ anode, tingkat korosi terendah adalah 1,448 mpy. Dalam penelitian ini, anoda $\mathrm{Al}$ terbukti efective untuk melindungi baja karbon pada jarak $1 \mathrm{~cm}$, dan dengan efektivitas $69,06 \%$ [9].

Perlindungan katodik untuk struktur beton yang diperkuat dengan cara anoda kurban seng adalah teknologi perlindungan korosi yang sangat efektif di lingkungan laut [10].

Berdasarkan hasil wawancara dengan pemilikpemilik kapal yang beroperasi di perairan Maluku tentang efisiensi penggunaan zink anoda dijelaskan bahwa ada yang menggunakan zink anoda lebih, dan ada juga yang kurang daripada yang diharuskan karena dari hasil ultrasonik terbukti bahwa dengan menambah zink anoda laju korosi yang diperoleh pada tahun berikutnya mengalami penurunan.

Adapun masalah yang ditinjau adalah kebutuhan kuat arus terpasang pada zink anoda yang masih belum mencukupi kebutuhan kapal. Masalah ini ditinjau karena berhubungan langsung dengan efisiensi kerja dari zink anoda, yang dari hasil perhitungan akan terlihat apakah masalah yang ditinjau tersebut berpengaruh pada laju korosi pada pelat lambung basah kapal baja.

Tujuan penelitian ini adalah untuk mengetahui pengaruhkuat arus zink anoda terpasang terhadap laju korosi kapal baja.

\section{BAHAN DAN METODE}

Korosi adalah penurunan mutu logam akibat reaksi elektrokimia dengan lingkungannya. Korosi dapat terjadi apabila memiliki anoda, katoda, media elektrolit, adanya arus listrik akibat pergerakan elektron [6].

Diperlukan data ukuran pokok 9 buah kapal yang menggunakan anoda tumbal tipe zink anodadan data ketebalan pelat kapal setiap tahun selama 5 tahun. Untuk mendapatkan data berat pelat terkorosi dengan cara merubah pengurangan ketebalan pelat $(\mathrm{mm})$ tiap tahun ke dalam ukuran weight loss (gr) untuk mendapatkan laju korosi dari persamaan berikut [11]: 


$$
C_{R}=87,6 \times\left(\frac{W}{D A T}\right)(\mathrm{mm} / \mathrm{tahun}
$$

di mana,

$$
\begin{aligned}
\mathrm{W} & =\text { massa yang hilang akibat terkorosi }(\mathrm{mg}) \\
\mathrm{D} & =\text { rapat massa }\left(\mathrm{gr} / \mathrm{cm}^{3}\right) \\
& =7.8 \mathrm{mgr} / \mathrm{m}^{3} \mathrm{atau} 490 \mathrm{lb} / \mathrm{ft}^{3} \\
\mathrm{~A} & =\text { luas permukaan }\left(\mathrm{in}^{2}\right) \\
\mathrm{T} & =\text { lama pengujian (hari). }
\end{aligned}
$$

\section{HASIL DAN PEMBAHASAN}

\subsection{Tabel dan Gambar}

Tabel 1. Kuat arus teoritis dan kuat arus terpasang

\begin{tabular}{cccccccccccc}
\hline \multirow{1}{*}{$\begin{array}{l}\text { I Butuh } \\
\text { Teoritis }\end{array}$} & \multicolumn{4}{c}{ Kuat Arus Terpasang } & \multicolumn{5}{c}{$\begin{array}{c}\text { Selisih Kuat Arus Teoritis dan } \\
\text { Kuat Arus Terpasang }\end{array}$} \\
\cline { 2 - 13 } & 1 & 2 & 3 & 4 & 5 & 1 & 2 & 3 & 4 & 5 \\
\hline 12.3 & 11.2 & 10.5 & 11.2 & 10.5 & 10.5 & 1.0 & 1.7 & 1.0 & 1.7 & 1.7 \\
13.4 & 14.6 & 14.6 & 14.6 & 17.6 & 17.6 & -1.2 & -1.2 & -1.2 & -4.2 & -4.2 \\
12.5 & 13.0 & 13.9 & 13.0 & 13.9 & 13.9 & -0.5 & -1.4 & -0.5 & -1.4 & -1.4 \\
10.9 & 11.3 & 11.3 & 11.5 & 12.7 & 12.7 & -0.4 & -0.4 & -0.7 & -1.8 & -1.8 \\
11.1 & 8.6 & 8.6 & 8.6 & 8.6 & 8.6 & 2.6 & 2.6 & 2.6 & 2.6 & 2.6 \\
9.0 & 9.0 & 8.3 & 8.6 & 6.4 & 8.6 & 0.1 & 0.1 & 0.5 & 2.7 & 0.5 \\
9.7 & 8.3 & 8.3 & 7.5 & 10.9 & 10.9 & 1.3 & 1.3 & 2.1 & -1.3 & -1.3 \\
15.3 & 7.3 & 7.3 & 7.3 & 7.9 & 7.9 & 8.0 & 8.0 & 8.0 & 7.4 & 7.4 \\
9.9 & 14.8 & 14.8 & 14.8 & 14.8 & 15.6 & -4.9 & -4.9 & -4.9 & -4.9 & -5.8 \\
\hline
\end{tabular}

Keterangan :

- I butuh teoritis = kuat arus total yang dibutuhkan

- Kuat arus terpasang (1) = kuat arus total yang mampu dikeluarkan oleh sejumlah anoda yang terpasang tahun pertama (Amp)

- Kuat arus terpasang (2) = kuat arus total yang mampu dikeluarkan oleh sejumlah anoda yang terpasang tahun kedua (Amp)

- Kuat arus terpasang (3) = kuat arus total yang mampu dikeluarkan oleh sejumlah anoda yang terpasang tahun ketiga (Amp)

- Kuat arus terpasang (4) = kuat arus total yang mampu dikeluarkan oleh sejumlah anoda yang terpasang tahun keempat (Amp)

- Kuat arus terpasang (5) = kuat arus total yang mampu dikeluarkan oleh sejumlah anoda yang terpasang tahun kelima (Amp)

- Selisih kuat arus yang dibutuhkan dengan kuat arus terpasang yang dikeluarkan oleh anoda tahun pertama

- Selisih kuat arus yang dibutuhkan dengan kuat arus terpasang yang dikeluarkan oleh anoda tahun kedua

- Selisih kuat arus yang dibutuhkan dengan kuat arus terpasang yang dikeluarkan oleh anoda tahun ketiga
- Selisih kuat arus yang dibutuhkan dengan kuat arus terpasang yang dikeluarkan oleh anoda tahun keempat

- Selisih kuat arus yang dibutuhkan dengan kuat arus terpasang yang dikeluarkan oleh anoda tahun kelima

Tabel 2. Laju Korosi Pada Kapal

\begin{tabular}{rccccc}
\hline & \multicolumn{5}{c}{ CORROSION RATE (mm/year) } \\
\cline { 2 - 6 } VESSEL & 1 & 2 & 3 & 4 & 5 \\
\hline 1 & - & 0.0310 & 0.0621 & 0.0155 & 0.1708 \\
2 & - & 0.0848 & 0.0509 & 0.0339 & 0.0339 \\
3 & - & 0.4433 & 0.0633 & 0.0317 & 0.0317 \\
4 & - & 0.2063 & 0.1100 & 0.0275 & 0.0138 \\
5 & - & 0.1270 & 0.0423 & 0.0564 & 0.0706 \\
6 & - & 0.2408 & 0.0459 & 0.0459 & 0.0688 \\
7 & - & 0.0612 & 0.0612 & 0.0245 & 0.0735 \\
8 & - & 0.2523 & 0.0194 & 0.0582 & 0.0388 \\
9 & - & 0.0989 & 0.0495 & 0.0495 & 0.0371 \\
\hline
\end{tabular}

Keterangan:

Corrosion Rate pada tahun pertama tidak mempunyai nilai karena merupakan titik awal yang mana laju korosi diambil dari pengurangan berat (weight loss) setelah satu tahun periode docking berlalu.

Analisis dilakukan pada 9 kapal, yang masingmasing dibuat dalam analisis tersendiri dengan memperhatikan permasalahan yang ditinjau. Dari 9 kapal yang ditinjau, hanya beberapa kapal yang akan ditampilkan dalam grafik hubungan korelasi yang terjadi antara selisih kuat arus teoritis dan kuat arus terpasang hubungannya dengan laju korosi.

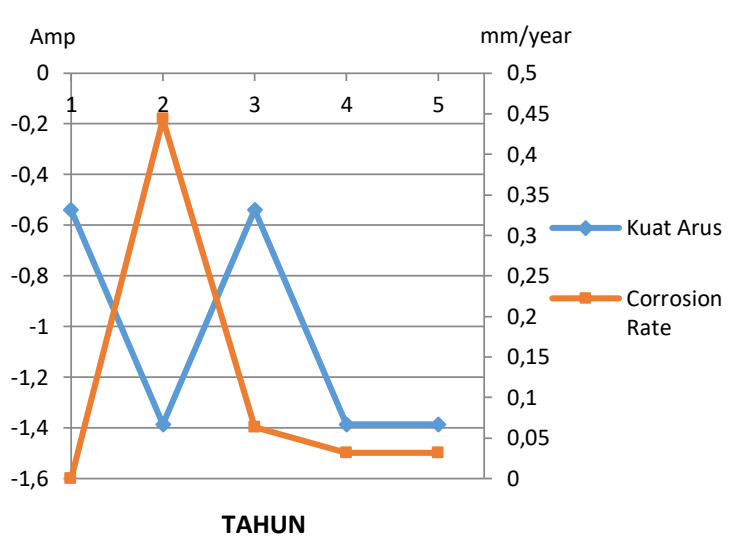

Gambar 1. Grafik korelasicorrosion rate dan selisih kuat arusteoritis dan kuat arus terpasang pada kapal no. 3

Pada tahun ke-2 hingga tahun ke-5 dalam Gambar 1 terlihat kuat arus terpasang mencukupi 
kebutuhan kapal ini dengan kelebihan arus antara 0,539 Amp hingga 1,386 Amp.Pada tahun ke-3 dengan kuat arus lebih 0,539 Amp terjadi laju korosi $0,0633 \mathrm{~mm} /$ tahun terus terjadi penurunan hingga tahun ke-5 dengan kuat aruslebih 1,386 Amp laju korosi mencapai $0,0317 \mathrm{~mm} / \mathrm{tahun}$.

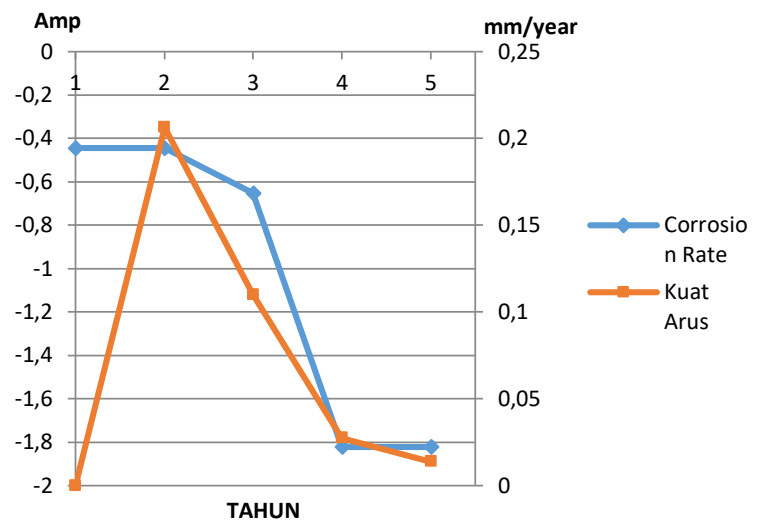

Gambar 2. Grafik korelasi corrosion rate dan selisih kuat arusteoritis dan kuat arus terpasang pada kapal no. 4

Pada Gambar 2 di atas terlihat kuat arus terpasang mencukupi kebutuhan kapal nomor 4, kelebihan kuat arus masih dalam batas normal. Pada tahun ke-2 dengan kuat arus lebih 0,444 Amp, pada tahun ke-3 hingga tahun ke-5 dengan kelebihan kuat arus terpasang 1,822 Amp terjadi penurunan laju korosi sebesar 0,0138 mm/tahun.

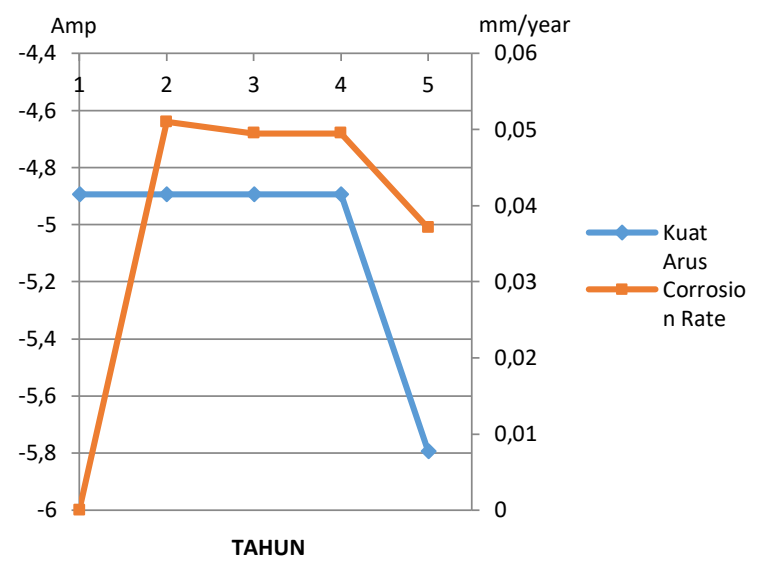

Gambar 3. Grafik korelasi corrosion rate dan selisih kuat arus teoritis dan kuat arus terpasang pada kapal no. 9

Dari grafik pada Gambar 3, kuat arus terpasang terlihat sangat mencukupi bahkan lebih jika dibandingkan dengan gambar 1 dan gambar 2. Tahun ke- 2 hingga tahun ke-4 dengan kuat arus terpasang lebih yang sama besar 4,894 Amp terjadi penurunan laju korosi tahun ke-2 sebesar $0,051 \mathrm{~mm} /$ tahun hingga pada tahun ke- 4 mencapai $0,0495 \mathrm{~mm} / \mathrm{tahun}$. Pada tahun ke-5 kelebihan arus naik menjadi 5,793 Amp mencapai laju korosi sebesar 0,0371 mm/tahun,

\section{KESIMPULAN}

Pada ketiga kapal terlihat jelas bahwa kebutuhan kuat arus terpasang tidak boleh kurang dari kuat arus secara teoritis. Kuat arus terpasang harus mencukupi kebutuhan masing-masing kapal karena berpengaruh terhadap penurunan laju korosi. Pada kapal No.3, No.4, dan No.9 terlihat bahwa kuat arus terpasang sangat mencukupi kebutuhan kapal.Pada Kapal No.3 ada kelebihan kuat arus 0,539 Amp-1,386 Amp terjadi penurunan laju korosi mencapai $0,0317 \mathrm{~mm} / \mathrm{tahun}$ pada tahun ke-5. Pada kapal No. 4ada kelebihan kuat arus 0,444 Amp-1,822 Amp terjadi penurunan laju korosi mencapai $0,0138 \mathrm{~mm} / \mathrm{tahun}$ pada tahun ke-5.Pada kapal No. 9 ada kelebihan kuat arus 4,894 Amp-5,793 Amp terjadi penurunan laju korosi mencapai $0,0371 \mathrm{~mm} /$ tahun pada tahun ke-5.

\section{UCAPAN TERIMA KASIH}

Ucapan terimakasih kepada Fakultas Teknik Universitas Pattimura sebagai penyandang dana (dana PNBP Fakultas Teknik tahun 2020) sehingga penelitian ini dapat selesai sesuai jadwal yang ditetapkan.

\section{DAFTAR PUSTAKA}

[1] Team The Naval Arch - Ship Corrosion Cathodic Protection and Sacrificial Anodes [https://thenavalarch.com/ship-corrosioncathodic-protection-sacrificial-anodes/] (Diakses tanggal: 27Maret 2017).

[2] Class Guideline DNVGL-CG-0288, Corrosion Protection of Ships, Edition May 2017.

[3] Komalasari, Komalasari \& Evelyn, Evelyn \& Situmeang, I \& Heltina, Desi. (2020). Cathodic protection on stuctures of carbon steel using sacrificial anode methode for corrosion control. IOP Conference Series: Materials Science and Engineering. $\quad 845$. 012015. 10.1088/175899X/845/1/012015.

[4] Cleophas Akintoye Loto, Roland Tolulope Loto, Abimbola Patricia Popoola, Performance evaluation of zinc anodes for cathodic protection of mild steel corrosion in HCL, Chemical Data Collections, Volume 24, 2019, 100280, ISSN 2405-8300

[5] Bambang S., Purwo J. S., Hernia S.: Analisis Kebutuhan Pemasangan Zink Anode untuk Mencegah Korosi pada Lambung Kapal General Cargo, Bina Teknika Vol 14, 2018.

[6] Ngatmin, Ngatmin \& Purwanto, Helmy \& 
Riwayati, Indah. (2019). Analisis Laju Korosi Pada Plat Baja Lambung Kapal dengan Umpan Anoda Korban Aluminium. Jurnal Ilmiah Momentum. 15. 10.36499/jim.v15i2.3085.

[7] Sunarto Sunarto, Deni Septian. (2015). Analisa Kebutuhan Anoda Korban Seng Pada Plat Bottom Kapal Di PT. Indonesia Marina Shipyard. Wahana Teknik. Vol 4 No.1.

[8] Noor Idora, M. M. Rahman, M. Ismail, W. B. Wan Nik. (2014). Effect of Zinc Coating Thickness on Corrosion Performance of Mild Steel in Atmospheric and Seawater Environment. Applied Mechanics and Materials. Vol. 554. Pp.213-217.
[9] A. A. T. Adriana, Komalasari, Drastinawati. (2018). Pengendalian Laju Korosi Baja dalam Air Laut Dengan Menggunakan Proteksi Katodik Metoda Anoda Korban. Jom FTeknik Volume 5 Edisi 2 juli s/d Desember

[10] Jeong, J. A. (2015). Cathodic Protection Effect of Reinforced Concrete Beam Specimens with Zinc Sacrificial Anode in Marine Environment. Advanced Materials Research, 1125, 345-349. https://doi.org/10.4028/www.scientific.net/a mr.1125.345

[11] Trethewey, K. R. Korosi untuk Mahasiswa dan Rekayasawan. Penerbit PT Gramedia Pustaka Utama, Jakarta 1993. 